\title{
Comentário l:
}

\section{Processo curatorial, museus antropológicos e descolonização}

\section{Comment I:}

Curatorial process, anthropological museums and decolonization

\section{CAMILA AZEVEDO DE MORAES-WICHERS}

https:// orcid.org/0000-0002-8996-7183

Universidade Federal de Goiás / Goiânia, GO, Brasil

O texto de Camilo de Mello Vasconcellos apresenta uma análise pertinente a respeito da trajetória dos processos curatoriais em museus antropológicos e etnográficos. Historiador por formação, o autor fornece a moldura histórica desse percurso. Baseado em referências sólidas e privilegiando autorias brasileiras, dos Estados Unidos e da Europa, Vasconcellos constrói um texto com pelo menos três qualidades: aproxima e informa leitoras/es iniciantes no tema, e identifica questões inovadoras para especializadas/os no campo dos museus antropológicos; valoriza as experiências vividas no país, formulando um texto à altura das contribuições brasileiras para as transformações da curadoria em museus antropológicos; provoca reflexões sobre as práticas desenvolvidas, instigando a descolonização dessas.

As inquietações trazidas por Vasconcellos me estimulam a lançar mais algumas ideias para debate, prolongando as reflexões do autor. Esses comentários não são complementos ao texto original, de consistência própria; são, antes, fios puxados da tecitura de sua narrativa a partir da minha vivência do tema. Assim como o autor, que acertadamente menciona a gravidade do momento que vivemos

\begin{abstract}
1. Bacharel e licenciada em história pela Universidade de São Paulo (USP), mestra e doutora em arqueologia pelo Programa de Pós-Graduação do Museu de Arqueologia e Etnologia (MAE) da USP. Doutora em museologia pela Universidade Lusófona de Humanidades e Tecnologias de Lisboa. Atualmente é professora do curso de museologia da Faculdade de Ciências Sociais da Universidade Federal de Goiás (FCS-UFG) e docente permanente do Programa de Pós-Graduação em antropologia social (PPGAS-UFG). E-mail: <camilamoraes@ ufg.br $>$.
\end{abstract}


2. Termo utilizado por Anne McClintock (2010).

3. O MAE-USP integra coleções etnográficas e arqueológicas das populações ameríndias, com ênfase no território brasileiro, assim como coleções africanas, afro-brasileiras, do Mediterrâneo e do Médio Oriente antigo. Contudo, serão abordadas as ações com coleções relacionadas aos povos indígenas do Brasil.

4. Um exemplo é a Coleção Lagoa Miararré, do Museu Antropológico da Universidade Federal de Goiás, formada por vasilhas, estatuetas e fragmentos cerâmicos coletados no fundo da lagoa, localizada no Xingu, por indígenas Kamaiurá. Essa coleção está dividida entre a Reserva Etnográfica (que recebeu as peças mais integras e esteticamente atrativas) e a Reserva Arqueológica (em que foram depositados os materiais fragmentados e sem apelo estético) do museu (MORAES-WICHERS, 2019).

5. A referência ao conceito de colecionamento de James Clifford (1994) não significa a adoção integral das críticas que ele dirige aos museus no âmbito do que tem sido identificado como antropologia "pós-moderna” (GORDON; SILVA, 2005). no que diz respeito à sobrevivência das sociedades indígenas de nosso país, escrevo sensibilizada pelo contexto da pandemia, que expõe ainda mais a trama da ordem colonial, ${ }^{2}$ bem como a relevância dos museus, dos processos curatoriais e da construção das memórias neste momento de resistência ao quadro atual.

Selecionei três aspectos a serem comentados de forma breve, a saber: (1) as fronteiras fluidas entre coleções etnográficas e arqueológicas; (2) o conceito de curadoria e de processo curatorial museológico nos museus antropológicos universitários; e (3) o potencial de atuação dos processos curatoriais museológicos nas fissuras da ordem colonial, sobretudo no Brasil, tendo em vista os diálogos possíveis e necessários com as ontologias e epistemologias indígenas.

Este dossiê aborda a noção de curadoria nos museus universitários e nas disciplinas às quais estão vinculados. Enfatizarei, em alguns pontos de diálogo com o artigo de Vasconcellos, processos curatoriais museológicos nos referidos museus - em especial no Museu de Arqueologia e Etnologia da Universidade de São Paulo (MAE-USP), ainda que não me atenha somente a eles. ${ }^{3}$

\section{ENTRE COLEÇÕES ETNOGRÁFICAS E ARQUEOLÓGICAS}

O autor nos adverte, na primeira nota do texto, de que não abordará as coleções arqueológicas, ainda que reconheça a sua importância para os museus antropológicos. Não obstante, gostaria de puxar esse fio, visto que as reflexões trazidas por Vasconcellos são profícuas para discussões a respeito das denominadas coleções arqueológicas. Justifico esta abordagem por compreender que essas coleções são fruto de ações disciplinares distintas, mas que evidenciam semelhanças e trânsitos. As fronteiras entre coleções arqueológicas e etnográficas são, por vezes, tênues. ${ }^{4}$

Como sugere James Clifford, podemos definir etnografia como "uma forma de colecionar cultura", envolvendo "os modos como os diversos fatos e experiências são selecionados, reunidos, retirados de suas ocorrências temporais originais" e transferidos para um novo arranjo. ${ }^{5}$ Ao dialogar com Clifford, compreende-se a prática etnográfica como uma forma de colecionar e evidencia-se uma longa trajetória de colecionamento do Outro, na qual antropologia e arqueologia ałuaram. Essa trajetória histórica deve ser considerada nos processos curatoriais museológicos desenvolvidos na contemporaneidade, como bem explicita Vasconcellos.

Enquanto a arqueologia tende a exercitar suas práticas de colecionamento por meio da seleção de objetos descartados - ou seja, objetos que estão fora do 
"contexto de uso" -, a antropologia, ao formar coleções etnográficas, deslocou os objetos do "contexto de uso" para o contexto museal. Não se pode ignorar que ambas as disciplinas foram orientadas por premissas teóricas semelhantes, do evolucionismo e difusionismo ao particularismo e relativismo cultural, chegando aos debates contemporâneos acerca do colonialismo e da necessidade premente de práticas mais simétricas.

Ao examinar a trajetória histórica das instituições brasileiras e, em especial, de museus universitários como o MAE-USP, observa-se que as bases de suas coleções foram estabelecidas ainda no século XIX, quando a especialização disciplinar ainda não delimitava fronteiras evidentes; quiçá ainda hoje não seja possível afirmar que essas fronteiras estão bem delimitadas. Isso porque, como apontarei, as práticas que visam a descolonização dos museus por meio do diálogo intercultural com os povos indígenas devem estar alinhadas ao fato de que a delimitação entre coleções etnográficas e arqueológicas é moderna e ocidental, uma vez que objetos classificados como arqueológicos ou etnográficos podem compor, para esses povos, mecanismos semelhantes de significação.

Visões sobre a alteridade foram incorporadas pelos museus antropológicos, de acordo com o texto de Vasconcellos. Penso que a prática arqueológica também é um dos dispositivos que constroem essas visões. A arqueologia brasileira, ao nomear como pré-coloniais ou mesmo pré-históricos ${ }^{6}$ os processos que se remetem a histórias de longa duração dos povos indígenas, distanciou as coleções arqueológicas dos debates antropológicos, resultando num estranhamento entre as disciplinas, o que já foi apontado por diversos estudos. Apesar disso, o texto de Vasconcellos fornece insumos para essa aproximação, ainda que não se comprometa a fazê-la. $\bigcirc$ autor menciona a antropologia física e as expedições de cunho científico promovidas por governos estrangeiros no Brasil, aspectos relacionados também com as coleções arqueológicas.

Ademais, as mudanças expostas pelo autor nos processos curatoriais museológicos desenvolvidos no MAE-USP também têm sido construídas em torno de um diálogo frutífero entre antropologia, arqueologia e museologia, como também a partir dos projetos desenvolvidos por Marília Xavier Cury e Fabíola Silva, mencionados no texto. Destarte, o artigo de Vasconcellos, ao construir um quadro histórico e analítico da curadoria em museus antropológicos, também apresenta questões instigantes para a musealização da arqueologia. A experiência do autor no MAE-USP deixa entrever um olhar integrado a respeito da curadoria, conforme exposto em sequência.
6. Anne McClintock afirma que os prefixos "pós" e "pré" conferem ao colonialismo o status de história propriamente dita, de forma que "outras culturas compartilham apenas uma relação preposicional a uma era eurocêntrica que acabou (pós) ou que ainda nem começou (pré)" (2010, p. 30). 
7. Bruno (2015) enfatiza o conceito de processo curatorial museológico e, mais recentemente, tem sugerido a noção de processo museológico-curatorial, dando ênfase à contribuição da museologia.

8. Ribeiro (1994).

9. Termo presente na Resolução $\mathrm{n}^{\circ} 5.937$, de 26 de julho de 2011, que apresenta o regimento do MAE-USP (UNIVERSIDADE DE SÃO PAULO, 2011).

10. Cf. Haiganuch Sarian (1999) e Bruno, op. cit.

11. É interessante notar que, no caso da Coleção Plínio Ayrosa, que pertencia ao Departamento de Antropologia da Faculdade de Filosofia, Letras e Ciências Humanas da USP, nenhum profissional "veio" com a coleção. A fusão representou, para as demais coleções, o deslocamento de profissionais do Museu Paulista e do corpo técnico das demais instituições.

\section{SOBRE PROCESSOS CURATORIAIS MUSEOLÓGICOS}

A noção de curadoria tem sido ampliada e aplicada em diversos contextos e modelos institucionais, adquirindo centralidade no cotidiano dos museus. $\bigcirc$ texto de Vasconcellos evoca em uma de suas passagens o conceito de "processo curatorial museológico". ? Passemos a deslindar esse aspecto do artigo.

Berta Ribeiro, ao analisar o panorama das coleções etnográficas no Brasil, evidencia que elas foram formadas, muitas vezes, de forma incoerente, sem um problema prévio de pesquisa ou a adoção de um vocabulário controlado para descrever os objetos. ${ }^{8}$ Vasconcellos salienta que na década de 1960 houve uma mudança no perfil de estudo das coleções etnográficas, que passou a ser formado também a partir de preocupações científicas. Da mesma forma, o autor aponta que, antes desse momento, a criação das universidades e a realocação de pesquisas antropológicas para tais espaços teria afastado as/os antropólogas/os dos museus e, junto com eles, os novos interesses esboçados pela antropologia. Essas mudanças ocorreram em tempos distintos e de forma desigual em diversas regiões do país, resultando em um legado marcado por desafios de monta. Os processos curatoriais museológicos assumem relevância diante desses desafios tanto por sua potencialidade em lidar com essas heranças como por integrar, no presente, a formação de coleções em um feixe concatenado de ações de pesquisa, documentação e comunicação museológicas.

Quando se fala em processo curatorial museológico, refere-se a um "ciclo completo"9 e contínuo de procedimentos técnicos e científicos que envolvem a formação das coleções e seu estudo, documentação, conservação e comunicação (exposição e ações educativas e de difusão cultural). Nessa abordagem, cada etapa é considerada em harmonia e de forma solidária com as demais, demandando um trabalho interdisciplinar.

Os processos curatoriais adquirem contornos específicos em museus antropológicos universitários, já que nessas instituições devem estar integrados as funções universitárias de ensino, pesquisa e extensão. ${ }^{10}$

Conforme indica Vasconcellos, no caso do MAE-USP - instituição resultante da fusão do Instituto de Pré-História, do antigo Museu de Arqueologia e Etnologia, dos acervos arqueológicos e etnográficos do Museu Paulista e do acervo etnográfico Plínio Ayrosa, ${ }^{11}$ cada qual com suas próprias trajetórias, premissas de pesquisa e políticas de acervos - buscou-se equacionar diferentes perspectivas em sua política curatorial. Nesse sentido, a compreensão da curadoria enquanto ciclo de atividades, expressa no próprio regimento do MAE-USP, tem possibilitado um aperfeiçoamento 
crescente do exercício das funções institucionais. A esse diálogo interdisciplinar, sempre inacabado e processual, soma-se o diálogo intercultural comentado a seguir.

\section{MUSEUS ANTROPOLÓGICOS E DESCOLONIZAÇÃO}

A década de 1980 acarretou ao campo dos museus antropológicos muitas mudanças, como bem expõe Vasconcellos. A antropologia viu-se como um mar revolto, agitado pelas ondas "pós-modernas" que colocaram em xeque a autoridade etnográfica. $\bigcirc$ contexto da época é marcado por críticas teóricas e também políticas, dado que a ligação entre prática antropológica e colonialismo já não podia ser negada.

Como aponta Regina Abreu, o diálogo entre a antropologia e os museus é uma história de lutas e embates. ${ }^{12}$ A autora oferece três chaves para a leitura desse diálogo, tecendo fios entre as antropologias reflexivas e os museus de ciência, entre as antropologias da ação e os museus como instrumentos de políticas públicas e entre as antropologias nativas e os museus como estratégias de movimentos sociais. Vasconcellos, acertadamente, investe grande parte de sua análise nessas últimas duas chaves.

autor mostra que se, por um lado, a crítica pós-moderna e pós-colonial indaga a respeito das trajetórias das coleções expostas nos museus antropológicos, compreendidas muitas vezes como espólios e despojos, por outro lado assiste-se a uma retomada dos estudos antropológicos dedicados aos objetos, coleções, "troços, trecos ou coisas". 13

Se superficialmente esses movimentos parecem correr em direções opostas, ao observar mais a fundo é possível notar que ambos concorreram para uma reaproximação entre os museus e as teorias antropológicas - ainda que em novas chaves, como bem revela Vasconcellos.

Como pesquisador que tem a própria trajetória imbricada com a museologia, o autor não deixa de apontar um ingrediente essencial dessa transformação: a nova museologia, ${ }^{14}$ que surgiu e se expandiu a partir da década de 1970, marcada por práticas que visavam aproximar os museus da sociedade. Vasconcellos lembra que tais práticas influenciaram os museus antropológicos, tendo sido postas em ação por museus tradicionais de antropologia (universitários ou não) e em museus criados por populações indígenas (de países como Canadá, México, Colômbia, Equador, Peru, Guatemala, Paraguai e Brasil). ${ }^{15}$ Caracterizados por
12. Abreu (2008).

13. Expressão utilizada por um dos expoentes desse movimento, Daniel Miller (2013).

14. Como o autor aponta, na América Latina esse movimento teve como grande marco a Mesa Redonda de Santiago do Chile, em 1972. Na década de 1980 foi criado formalmente o Movimento Internacional para uma Nova Museologia, atualmente parte do Conselho Internacional de $\mathrm{Mu}$ seus. O surgimento dos museus de sociedade, ecomuseus, museus comunitários, entre outros, bem como de denominações como museologia social, sociomuseologia e museologia comunitária também fazem parte desse processo.

15. No século XXI as políticas públicas voltadas ao campo dos museus fortaleceram esse quadro, algo que não pode ser menosprezado, como nos indica Vasconcellos. 
16. Isso é fruto de mais de uma década de trabalho de Gomes (2019), apresentado em sua tese de doutorado.

17. Gomes (2019) menciona que já em 1995 foi criado o Museu dos Kanindé de Aratuba, no Ceará. avanços, recuos, olhares divergentes, negociações e acordos possíveis, esses processos também têm trazido mudanças significativas para a noção de curadoria.

Comecemos puxando o fio dessas transformações por meio das experiências dos museus indígenas. Vasconcellos aponta dois museus da categoria que se destacam: o Museu Magüta, primeiro museu indígena do país, e o Museu Kuahí dos povos do Oiapoque; ambos indígenas, mas com a participação das antropólogas Jussara Gomes Gruber e Lux Vidal, respectivamente. Em 2019, Alexandre Gomes indicou a existência de 43 museus indígenas no país. Ao transitar pelas noções de etnomuseografia, de ação museológica indígena, de "cosmopolíticas da memória" e de apropriação e tradução, ${ }^{16}$ Gomes demonstra que o conceito de museu indígena pode ser examinado como categoria classificatória, como categoria nativa e como fenômeno social. Dessa forma, o quadro sinalizado por Vasconcellos, no que concerne aos museus criados por indígenas, é vigoroso (em especial na região nordeste) $)^{17}$ e envolve a apropriação e a ressemantização dos museus a partir das ontologias e epistemologias indígenas. A criação da Rede Indígena de Memória e Museologia Social, em 2014, também mostra essa efervescência.

No âmbito da indigenização dos museus antropológicos, Vasconcellos menciona a experiência da exposição "Tempo e espaço na Amazônia - os Waiãpi no Museu do Índio do Rio de Janeiro", em 2002, quando indígenas Wajãpi participaram da seleção dos objetos e construíram uma casa no espaço externo do museu. Indubitavelmente, a própria criação do Museu do Índio, na década de 1950, é um ponto importante da trajetória histórica dos museus antropológicos no país. O mencionado afastamento da antropologia dos museus (ou dos chamados estudos de cultura material) merece um olhar atento sob o contexto brasileiro, uma vez que as/os antropólogas/os continuaram a formar coleções como parte das relações de amizade e parentesco com os povos que estudavam. Ainda que as coleções não fossem regidas por premissas orientadoras de uma "coleção científica", as materialidades fabricam os corpos e as pessoas nas sociedades indígenas, assim como fazem parte dos trânsitos entre "eles/as" e "nós"; por isso, as coleções e os museus sempre estiveram à espreita da prática antropológica.

Vasconcellos se detém em duas experiências vivenciadas no MAE-USP: o projeto realizado por Fabíola Silva com os Asurini do Xingu, em 2005, e a exposição "Resistência Já" com os povos Kaingang, Guarani Nhandeva e Terena, sob a coordenação de Marília Xavier Cury, em 2019. A essas experiências, adiciono o trabalho "Objetos vivos: a curadoria da coleção etnográfica XikrinKayapó", que chegou ao MAE-USP em 200 1, também coordenado por Fabíola Silva e com a participação de Gordon. Ao articular antropologia, museologia, conservação e outras áreas acadêmicas, a experiência se apresenta como uma 
abordagem interdisciplinar; e mais do que isso: ao invocar os olhares dos próprios indígenas sobre os objetos, se coloca como um diálogo intercultural.

Os museus antropológicos têm raízes na modernidade ocidental, marcados pelos processos de colonização tanto do ponto de vista da origem de suas coleções - muitas vezes obtidas por saques acompanhados de extermínio - como pelos regimes de visibilidade que constroem sobre essas populações. Dualismos cartesianos como passado/presente, natureza/cultura e objeto/sujeito, que estabelecem diferenças dicotômicas e hierarquizadas, estão presentes nestes regimes. Para além de discussões acerca do repatriamento e da restituição, bem como da necessidade que os museus explicitem a origem de suas coleções lesforço que demanda pesquisa e ratifica o caminho acertado do processo curatorial como ciclo completo), as transformações epistemológicas que embasam o processo curatorial e seus regimes de visualidade também compõem esse quadro.

texto de Vasconcellos mostra que as formas de indigenização dos museus são diversas ${ }^{18}$ tanto no que se refere aos processos realizados nos "museus do Outro" como nos "museus de Si". Utilizo esses termos em diálogo com Bruno Brulon Soares, sendo os "museus do Outro", por excelência, os museus etnográficos, e os museus de si, os ecomuseus - no âmbito da análise do contexto francês analisado por Brulon. ${ }^{19}$ Nesse sentido, os museus indígenas seriam os "museus de Si", mas um "Si" aberto à alteridade, aspecto próprio dos povos indígenas.

Marília Xavier Cury argumenta que os profissionais, visitantes, constituents - de quem se fala no museu, os integrantes das culturas relacionadas ao museu - e encantados ${ }^{20}$ são curadores. Coletas, pesquisas com as coleções e nos arquivos que mapeiam suas trajetórias, estudo e produção de narrativas audiovisuais, documentação, conservação e comunicação museológicas têm sido, assim, afetadas por novas agências no processo curatorial. Essa "museologia encantada", nas palavras de Gomes, ${ }^{21}$ insere os ancestrais, pajés e xamãs na cadeia operatória museológica.

Como bem sintetiza Vasconcellos, esse contexto "interfere em todas as etapas" de trabalho dos museus antropológicos, exigindo "novos procedimentos". $\bigcirc$ museu passa a ser um espaço de fricção, lugar de confluência, diálogo, negociação, acordo, restituição e reconciliação. Um outro elemento desse processo é a indigenização das próprias universidades, com o acesso de estudantes indígenas a diversos cursos de graduação e pós-graduação, com especial presença nos campos da educação e da antropologia. Esse movimento já chega às portas dos museus.

A curadoria em museus antropológicos enseja, assim, muitas camadas de significação: as coleções são heranças de processos diferenciados, dizendo muito a respeito da história da Antropologia no país, e revelam os olhares interpretativos
18. Existe uma crescente produção analítica sobre o tema. Em 2019 foram elaborados ao menos três dossiês com o tema: Coleções Etnográficas e Processos Museológicos, da revista Anthropológicas, Antropologia dos Museus, da Horizontes Antropológicos, e Museus e Acervos Arqueológicos e Etnográficos: (Re)leituras e Experiências, da revista $\mathrm{Ha}$ bitus. Diversos livros também têm sido publicados, dentre os quais destacam-se as obras organizadas por Oliveira e Santos (2019), Porto e Lima Filho (2019), Renato Athias e Alexandre Gomes (2016), e a publicação da ABA, organizada por Lima Filho, Abreu e Athias (2016). A coleção Museu Aberto tem abrigado livros sobre questões indígenas e museus desde 2012, somando cinco livros produzidos pela parceria entre a Acam Portinari e o MAE-USP.

19. Soares (2012).

20. A inserção dos encantados no processo de curadoria merece destaque, uma vez que são responsáveis por decisões sobre o que pode ou não ser musealizado, aquilo que pode ou não ser visto, como indica Cury (2020).

21. Gomes, op. cit. 
das instituições das quais fazem parte, suas transformações e escolhas curatoriais. Por fim, as coleções oportunizam distintas relações com os povos indígenas. Com relação aos públicos não indígenas, Vasconcellos questiona: como seria se povos indígenas pudessem construir representações sobre as sociedades não indígenas nos museus? Adiciono: quais reflexos veríamos em espelhos agora voltados para nós mesmos? É possível que esse caminho, indicado pelo autor, seja um dos mais frutíferos percursos da descolonização dos museus. 


\section{REFERÊNCIAS}

LIVROS, ARTIGOS E TESES

ABREU, Regina. Tal antropologia, qual museu? Revista do Museu de Arqueologia e Etnologia, São Paulo, p. 121-143, 2008. Doi: <https://doi.org/10.11606/issn.2594-5939. revmaesupl.2008.113502>.

ATHIAS, Renato; GOMES, Alexandre. Coleções etnográficas, museus indígenas e processos museológicos. Recife: Editora UFPE, 2016.

BRUNO, Maria Cristina Oliveira. Os reflexos dos 25 anos do Museu de Arqueologia e Etnologia nos 80 anos da USP. In: GOLDEMBERG, José (org.). USP 80 anos. São Paulo: Edusp, 2015. v. 1, p. $245-250$.

CLIFFORD, James. Colecionando arte e cultura. Revista do Patrimônio Histórico e Artístico Nacional, São Paulo, n. 23, p. 69-89, 1994.

CURY, Marília Xavier. Metamuseologia? Reflexividade sobre a tríade musealia, musealidade e musealização, museus etnográficos e participação indígena. Museologia E Interdisciplinaridade, Brasília, DF, v. 9, n. 17, p. 129-146, 2020. Doi: <https://doi.org/10.26512/museologia.v9i17.29480>.

GOMES, Alexandre Oliveira. Museus indígenas, mobilizações étnicas e cosmopolíticas da memória: um estudo antropológico. 2019. Tese (Doutorado em Antropologia) - Universidade Federal de Pernambuco, Recife, 2019.

GORDON, Cesar; SILVA, Fabíola Andréa. Objetos vivos: a curadoria da coleção etnográfica Xikrin-Kayapó no Museu de Arqueologia e Etnologia - MAE/USP. Estudos Históricos, Rio de Janeiro, n. 36, p. 93-110, 2005.

LIMA FILHO, Manuel; ABREU, Regina; ATHIAS, Renato (orgs.). Museus e atores sociais: perspectivas antropológicas. Recife: Editora UFPE, 2016.

MCCLINTOCK, Anne. Couro imperial: raça, gênero e sexualidade no embate colonial. Campinas: Editora da Unicamp, 2010.

MILLER, Daniel. Trecos, troços e coisas: estudos antropológicos sobre a cultura material. Rio de Janeiro: Zahar, 2013.

MORAES-WICHERS, Camila Azevedo de. "Todo mundo ficou com medo desse caco": práticas de colecionamento e colonialidade na formação da coleção da Lagoa Miararré, Xingu. In: PORTO, Nuno; LIMA FILHO, Manuel (orgs.). Coleções étnicas e museologia compartilhada. Goiânia: Imprensa Universitária, 2019. p. 67-101. 
OLIVEIRA, João Pacheco de; SANTOS, Rita de Cássia Melo. De acervos coloniais aos museus indigenas: formas de protagonismo e de construção da ilusão museal. João Pessoa: Editora da UFPB, 2019.

PORTO, Nuno; LIMA FILHO, Manuel (orgs.). Coleções étnicas e museologia compartilhada. Goiânia: Imprensa Universitária, 2019.

RIBEIRO, Berta Gleizer. Etnomuseologia: da coleção à exposição. Revista do Museu de Arqueologia e Etnologia, São Paulo, n. 4, p. 189-201, 1994. Doi: <https://doi.org/10.11606/ issn.2448-1750.revmae.1994.109204>.

SARIAN, Haiganuch. Curadoria sem curadores? In: SEMANA DOS MUSEUS DA UNIVERSIDADE DE SÃO PAULO, 1., 1997, São Paulo. Anais [...]. São Paulo: Pró-Reitoria de Cultura e Extensão Universitária da USP, 1999.

SOARES, Bruno César Brulon. Máscaras guardadas: musealização e descolonização. 2012. Tese (Doutorado em Antropologia) - Instituto de Ciências Humanas e Filosofia, Universidade Federal Fluminense, Niterói, 2012.

UNIVERSIDADE DE SÃO PAULO. Resolução $\mathrm{n}^{\circ}$ 5.937, de 26 de julho de 2011. Baixa o Regimento do Museu de Arqueologia e Etnologia. Diário Oficial do Estado de São Paulo, São Paulo, 28 jul. 2011. Disponível em: <https://bit.ly/3cjlFz1>. Acesso em: 6 jun. 2020.

VAN VELTHEM, Lucia Hussak; KUKAWKA, Katia; JOANNY, Lydie. Museus, coleções etnográficas e a busca do diálogo intercultural. Boletim do Museu Paraense Emílio Goeldi: Ciências Humanas, v. 12, n. 3, p. 735-748, 2017. Doi: <https://doi.org/10.1590/1981.81222017000300004>.

Artigo apresentado em: 30/10/2020. Aprovado em: 30/1 1/2020. (cc) BY 